\title{
Relationship between microstructure homogeneity and bonding stability of ultrafine gold wire
}

\author{
Seoung-Bum Son • Hyunchul Roh • Suk Hoon Kang • \\ Hee-Suk Chung • Do Hyun Kim • Yong Seok Choi • \\ Jong Soo Cho $\cdot$ Jeong-Tak Moon $\cdot$ Kyu Hwan Oh
}

Published online: 17 November 2011

(C) The Author(s) 2011. This article is published with open access at Springerlink.com

\begin{abstract}
Inhomogeneous microtexture evolution during the cold drawing process usually results in lean, sway, or sweep failure. The $<111>$ longitudinal fiber texture has higher stiffness than the $<100>$ texture and its proportion and distribution in the cross-section are critical for the bonding stability of fine gold wire. We investigated the inhomogeneous microtexture evolution of gold wire that was cold drawn through an asymmetric diamond die. In this study, the distributions of the $<111>$ and $<100>$ textures in a $20 \mu \mathrm{m}$ diameter fine gold wire are the variables and their effects on the bonding stability of the wire were estimated by electron backscattered diffraction (EBSD) and finite element method (FEM) simulations. The use of a focused ion beam apparatus enabled a high quality of band contrast of the EBSD to be achieved in the exact half cross-sectional area of the fine gold wire. The detailed three-dimensional
\end{abstract}

S.-B. Son · H. Roh • D. H. Kim • Y. S. Choi · J. S. Cho •

K. H. Oh $(\bowtie)$

Department of Materials Science and Engineering,

Seoul National University,

Seoul 151-742, South Korea

e-mail: kyuhwan@snu.ac.kr

\section{S. H. Kang}

Nuclear Materials Research Division,

Korea Atomic Energy Research Institute,

1045 Daedeok-daero,

Yuseong-gu, Daejeon 305-353, South Korea

\section{H.-S. Chung}

Fundamental Technology Group, Central R\&D Institute,

Samsung Electro-Mechanics,

Suwon 443-743, South Korea

J. S. Cho $\cdot$ J.-T. Moon

MK electron,

316-2 Geumeo-ri, Pogok-myeon,

Yongin-si, Gyeong gi-do 449-810, South Korea
FEM results show that the asymmetric distribution of the textures plays a crucial role in increasing the spatial displacement of the gold bonding wire.

Keywords Gold bonding wire - Bonding stability EBSD . FEM

\section{Introduction}

Recently, gold bonding wire has been extensively used for the fabrication of integrated circuits (ICs) because of its good electrical conductivity and mechanical stability with a diameter of $20 \mu \mathrm{m}$ or less [1-3]. To advance the miniaturization of electronic packages, the process of creating gold bonding wire less than $\sim 20 \mu \mathrm{m}$ in diameter has been performed by repeated cold drawing through diamond dies until the desired diameter is achieved. Repeated cold drawing affects the microstructure of the gold bonding wires, which leads to an inhomogeneous texture due to the asymmetric deformation caused by the imbalanced contact with the dies. From this perspective, it is crucial to investigate the proper drawing conditions through several steps, which enable the fine gold bonding wire to provide a reliable interconnection and bonding stability in an electronic package. There have been many reports on the formation of undesirable intermetallic compounds between the bonding wire and metal pad, since they decrease the electric conductivity and durability [4-6]. The residual stress after cold drawing has also attracted attention in industry because it can reduce the mechanical properties of the wire, such as its yield strength and ultimate tensile strength [7, 8]. However, there have not been any microstructure or texture studies that dealt with the 
bonding stability until now. In this sense, our study focused on the microstructure and texture distribution of cold drawing gold bonding wire to reveal the inhomogeneity of the bonding stability in a microtextural way.

As regards the texture features in cold drawn gold bonding wire investigated using electron backscattered diffraction (EBSD) analysis, the $<100>$ and $<111>$ textures are observed with dominant crystal directions along the wire drawing direction [9-12]. In general, the $<100>$ and $<111>$ textures are located at the center and between the surface and center of the gold wire, respectively. Furthermore, the relative fraction of $\langle 100\rangle$ and $<111>$ textures is known to be controlled by the stacking fault energy of the materials and corresponding processes such as drawing (volume fraction of $<100>$ decreases and $<111>$ increases) and annealing $(<100>$ grains grow into $<111>$ grains during heat treatment) $[3,11,13,14]$.

When we consider that every single step in the reduction of the wire diameter is related to the shear deformation of the wire, which rotates the crystal directions from $<100\rangle$ to $<111>$, and that this shear deformation is caused by the contact with the diamond dies, it is clear that the dies play an important role in the symmetric or asymmetric texture evolution of the drawn wires. The inhomogeneity of shear deformation in the drawn wire results not only in a decrease of its draw ability, but also in a decrease of its physical properties, such as its electrical conductivity, current density, and mechanical properties [14-16]. In this research, the possible inhomogeneous deformation of fine gold drawn wire is analyzed in terms of the texture distribution using EBSD and the bonding stability of the drawn wire is investigated using FEM.

\section{Experimental procedures}

EBSD samples of gold wire were prepared by focused ion beam (FIB) milling. An FEI NOVA200 dual-beam system was used for the preparation of the gold wire samples. Sample preparation through FIB milling results in highquality EBSD band contrast [17, 18]. The ion source is liquid $\mathrm{Ga}$ metal and ion milling currents ranging from $50 \mathrm{pA}$ to $3 \mathrm{nA}$ and a constant accelerating voltage of $30 \mathrm{kV}$ were used for the gold wire milling. In this research, it is also important to achieve the exact half cross-sectional area of the drawn wire to define the symmetric wire deformation. By FIB milling, it is possible to obtain the exact half cross-sectional area of the drawn wire, which enables one to analyze the symmetric or asymmetric texture distributions during the drawing process. An HR-EBSD system (JEOL $6500 \mathrm{~F}$ with INCA/OXFORD EBSD system) was used for the measurement of the texture distribution of the gold wire. An accelerating voltage of $20 \mathrm{kV}$ and probe current of $4 \mathrm{nA}$ were used for this measurement.

The manner in which the asymmetric texture of the drawn gold wire affects its bonding stability is proven by FEM analysis. ABAQUS 6.9 and CATIA V5 software were used for this FEM research. The CPS4 (two-dimensional) and C3D8 (three-dimensional) element types were used in this process to investigate the arched shape problem of the gold bonding wire.

It has already been reported that gold wire has mechanical property anisotropy because it has a different Young's modulus depending on the crystal direction [19, 20]. The Young's modulus of each orientation is calculated based on the following equation.

$\frac{1}{E_{i j k}}=S_{11}-2\left(S_{11}-S_{12}-\frac{1}{2} S_{44}\right)\left(\lambda_{i 1}^{2} \lambda_{j 2}^{2}+\lambda_{j 2}^{2} \lambda_{k 3}^{2}+\lambda_{i 1}^{2} \lambda_{k 3}^{2}\right)$

where, $E_{\mathrm{ijk}}$ is the Young's modulus in the $[i j k]$ direction; $\lambda_{\mathrm{i} 1}$, $\lambda_{\mathrm{j} 2}$, and $\lambda_{\mathrm{k} 3}$ are the direction cosines of the directional [ijk]; and $S_{11}, S_{12}$, and $S_{44}$ are the elastic constants of an isotropic material given by

$S_{11}=\frac{1}{E} . \quad S_{12}=-\frac{v}{E} . \quad S_{44}=\frac{1}{G}$.

where, $E$ is the Young's modulus, $v$ is the Poisson ratio, and $G$ the shear modulus [21]. From the above equations, it is confirmed that each crystal direction has a different Young's modulus. In the case of gold, the $<111>,<110\rangle$, and $<100>$ crystal directions show Young's moduli of $116.28,81.47$, and $42.91 \mathrm{GPa}$, respectively.

The stress-strain curve of $20 \mu \mathrm{m}$ diameter gold wire is achieved for the purpose of applying its mechanical properties to FEM analysis. Table 1 compares the mechanical properties of the bulk gold to the fine gold wire. The reported yield stress and ultimate tensile strength of bulk gold are 205 and $120 \mathrm{MPa}$, respectively, but can be affected by the history and heat treatment. The remarkable differences in the mechanical properties of these two materials are due to the work hardening of the fine gold wire caused by the numerous cold drawing treatments and the increase of the proportion of $<111>$ texture in the fine drawing wire $[1,22,23]$.

Table 1 Mechanical properties of bulk gold and fine gold wire

\begin{tabular}{llll}
\hline Material & Parameter & Value & Unit \\
\hline Bulk gold & Young's modulus $(\mathrm{E})$ & 77.2 & $\mathrm{GPa}$ \\
& Yield stress $\left(\sigma_{\mathrm{y}}\right)$ & 205 & $\mathrm{MPa}$ \\
& Ultimate tensile strength & 120 & $\mathrm{MPa}$ \\
Fine gold wire & Young's modulus $(\mathrm{E})$ & 65.7 & $\mathrm{GPa}$ \\
& Yield stress $\left(\sigma_{\mathrm{y}}\right)$ & 484 & $\mathrm{MPa}$ \\
& Ultimate tensile strength & 538 & $\mathrm{MPa}$ \\
\hline
\end{tabular}




\section{Results and discussion}

After the gold wire is bonded, it can be seen that each wire has a different bonding shape and leans toward the other wires as shown in Fig. 1a, b. This nonstraightness problem has not been studied until now and the reason for this problem is also not known yet exactly. The drawing dies and microtexture distribution of the cold drawn gold wire is observed in an attempt to solve this problem.

As the bonding wire is formed by continuous cold drawing, its asymmetric deformation caused by the drawing dies is more or less effective depending on how the die and wire contact each other. Even if the wire has an inhomogeneous deformation resulting from the asymmetric dies, the inhomogeneity of the drawn wire can be increased or decreased by the subsequent drawing process. This can explain the locally observed arched bonding wire in Fig. 1. We should also consider that the asymmetric deformation in the drawn wire can occur not only leftward and rightward, but also forward and backward in the bonding wire.

Figure $1 \mathrm{a}, \mathrm{b}$ show the straight and arched bonding wires and the schematics of the corresponding drawing process with dies. In Fig. 1b, the unexpected connection between the bonding wires causes a short-circuit problem and this

(a) symmetric dies

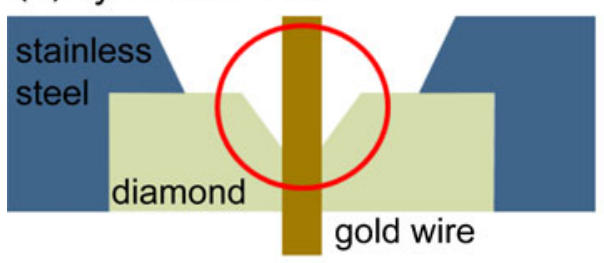

(b) asymmetric dies
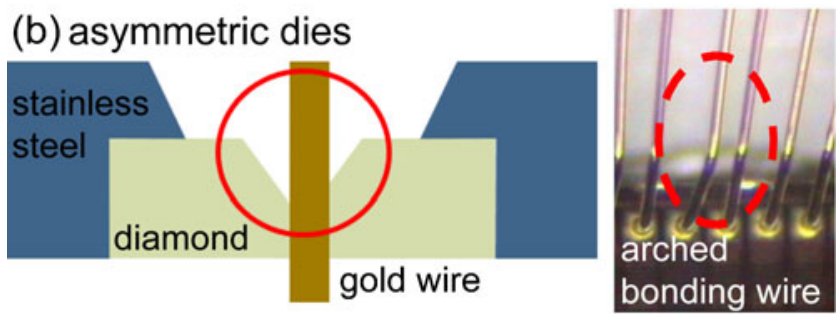

(c)

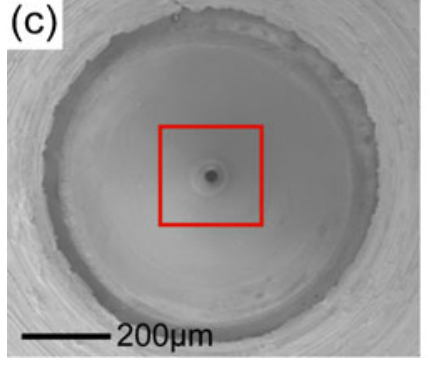

wire contact area

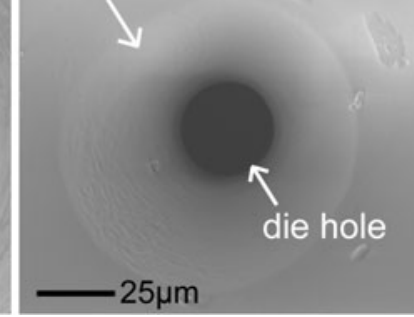

Fig. 1 Schematics, optical, and SEM images of drawing dies and the gold wire. a Symmetric dies and straight bonding wire. b Asymmetric dies and arched bonding wire. c SEM images of an asymmetric die leads to IC chip failure, which means the failure of the device. We observed the SEM images of the drawing dies as the bonding wire is drawn through them to find the reason for the straightness problem of the bonding wire. Figure 1c shows the SEM images of the drawing dies. It can be seen that the drawing die is damaged around the hole area during the wire drawing process. However, the drawing wire diameter reduction area does not have the shape of a perfect circle and it is not centered on the hole. This observation tells us that there is a possibility for the asymmetrical deformation of the gold wire to occur. Asymmetric rolling is used to deliver enough sheer strain to the whole volume of the object and reduce the pressure during rolling, however it can also cause an asymmetric texture distribution since the texture evolution in the cold drawn wire is highly related to the sheer deformation $[24,25]$.

A two-dimensional element type FEM simulation is used to quantify the relationship between the asymmetric shape of the die and displacement of the wire centerline and the $<100>$ fiber center line. Figures $2 \mathrm{a}$ and $\mathrm{b}$ show the simplified schematics of the symmetric and asymmetric drawing processes. The gold wire model in this FEM study is assumed to have a diameter of $20 \mu \mathrm{m}$ and be filled with $25 \%$ of $<100>$ fiber in the center area and $<111>$ fiber in the remaining area for the sake of simplicity. The volume fraction of $<111>$ and $<100>$ fiber is based on our EBSD study. The drawing die is designed to have a reduction ratio of $6 \%$ and reduction angle of $6^{\circ}$. The previously calculated mechanical properties of the $<111>$ and $<100>$ fibers of gold wire are applied in this model. It is assumed that the asymmetric dies have a spatial displacement compared to the symmetric dies. The spatial displacement between the symmetric dies and asymmetric dies is represented as a function of the displacement of the die. The spatial displacement of the wire center lines after drawing and the $<100>$ center line are represented as a function of $d_{100} / d_{\mathrm{w}}$. In Fig. 2b, even though the $<100\rangle$ center line also shows a spatial displacement after drawing according to our FEM study, it is represented as a straight line for the sake of providing easily perceptible schematics.

In Fig. 2c, the curve of $d_{100} / d_{\mathrm{w}}$ versus the displacement of the die is shown. As the displacement of the die increases, $d_{100} / d_{\mathrm{w}}$ increases as well. The curve generally shows linear behavior and makes it plain that the asymmetric shape of the dies affects the deformation tendency and results in the asymmetric deformation of the drawn wire. Considering that ultrafine gold wire is achieved by a large number of cold drawing processes, it is expected that ultrafine gold wire with an inhomogeneous microstructure can be produced in this way.

As shown in Fig. 3a, b, an EBSD analysis is performed to define the microstructure and differences of the texture distribution in the wires. Two samples of wire, one straight 


\section{(a) symmetric drawing}

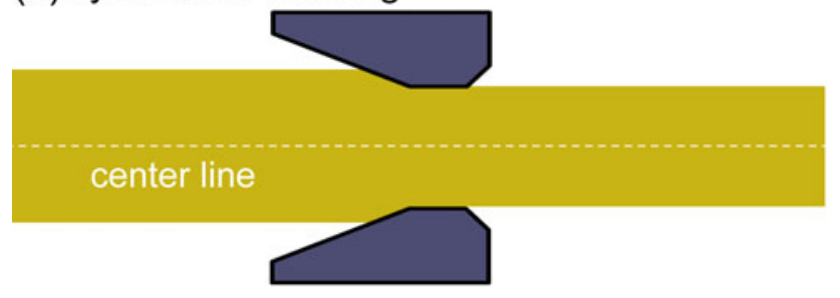

(b) asymmetric drawing
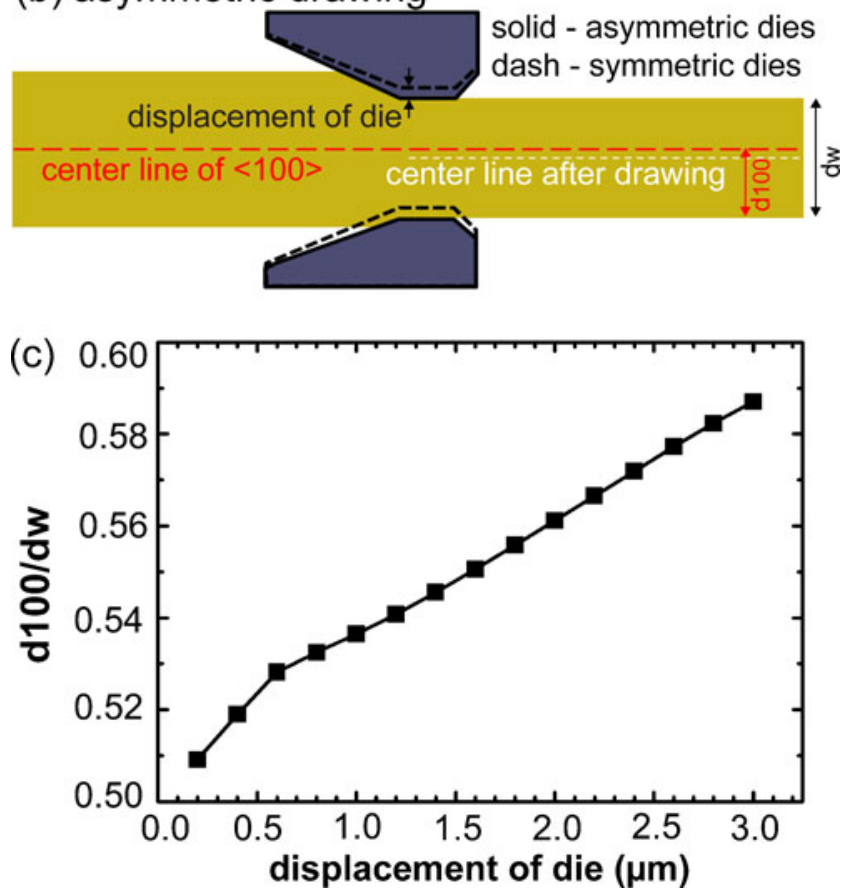

Fig. 2 Two-dimensional FEM simulation. a Schematic of symmetric drawing. b Schematic of asymmetric drawing. $\mathbf{c} d_{100} / d_{\mathrm{w}}$ with regard to displacement of die

and the other arched, were collected to compare their texture distributions. Figure 3a shows an FIB ion image and EBSD rolling direction (RD) map of the corresponding area in the straight wire. It is observed that most of the area in the center of the wire is filled with the $\mathrm{RD} / /<100>$ texture and that the $\mathrm{RD} / /<111>$ texture is mainly located on the surface area of the gold wire, as expected. It can also be observed that the gold wire has a symmetric texture distribution, which means that the gold wire has been subjected to symmetric deformation, as the $\mathrm{RD} / /<100>$ fibers are replaced by $\mathrm{RD} / /<111>$ ones during cold drawing [3].

In Fig. 3b, however, the problem we are interested in is that the $\mathrm{RD} / /<100>$ texture in the arched wire is not located at the exact center of the wire. It is observed that the $<100>$ direction is not located in the exact center of the wire and that the value of $d_{100} / d_{\mathrm{w}}$ is approximately 0.6 . As shown in our FEM results, the $\mathrm{RD} / /<100>$ texture, which is not located in the exact center of the drawn wire, indicates that
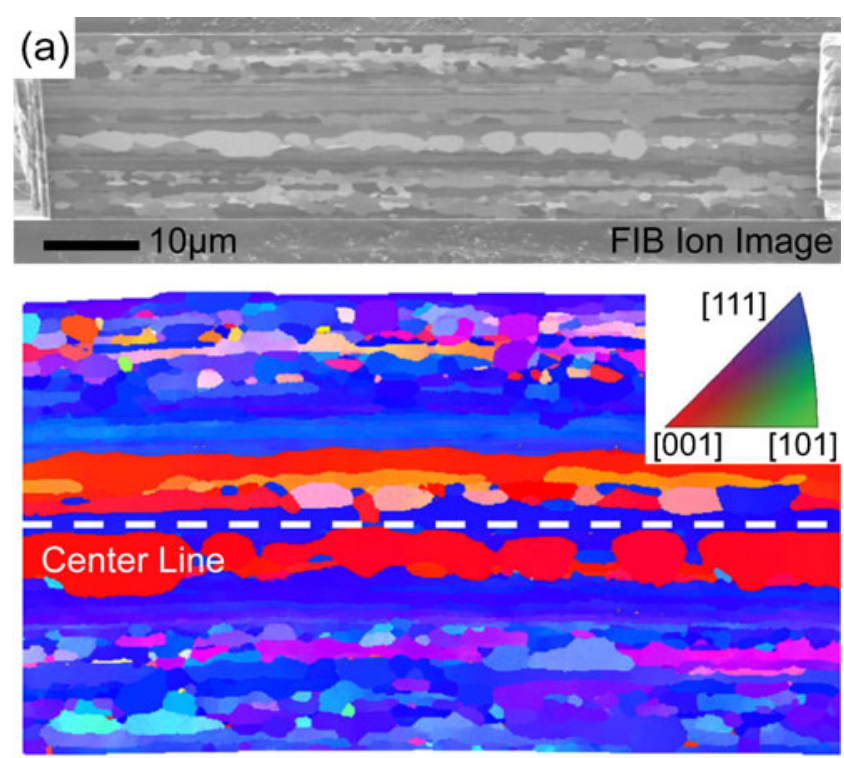

$5 \mu \mathrm{m}$

Rolling Direction
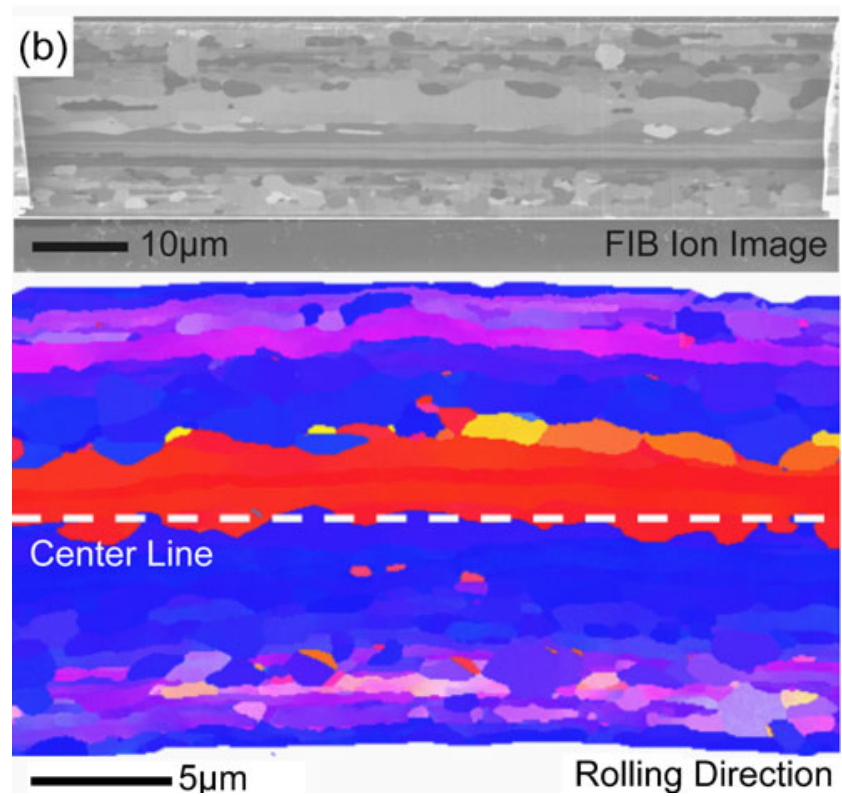

Fig. 3 FIB ion images and EBSD RD mappings of $20 \mu \mathrm{m}$ gold wire. a Straight gold drawing wire and orientation color key. b Arched gold drawing wire

the drawn gold wire underwent asymmetric deformation while being drawn through the drawing dies.

Three-dimensional FEM models are applied to analyze this arched wire problem and the simulation models used in this research are shown in Fig. 4a. We assumed that the drawn gold wire is simply composed of two crystal directions, $<100\rangle$ and $<111>$, even though there are some other mixed crystal directions at the wire surface. The location of the $<100>$ direction in each model is represented by $d_{100} / d_{\mathrm{w}}$ and has approximate values of $0.6,0.7,0.8$, and 0.9 in the four models, respectively. The diameter of the $<100>$ direction area is 

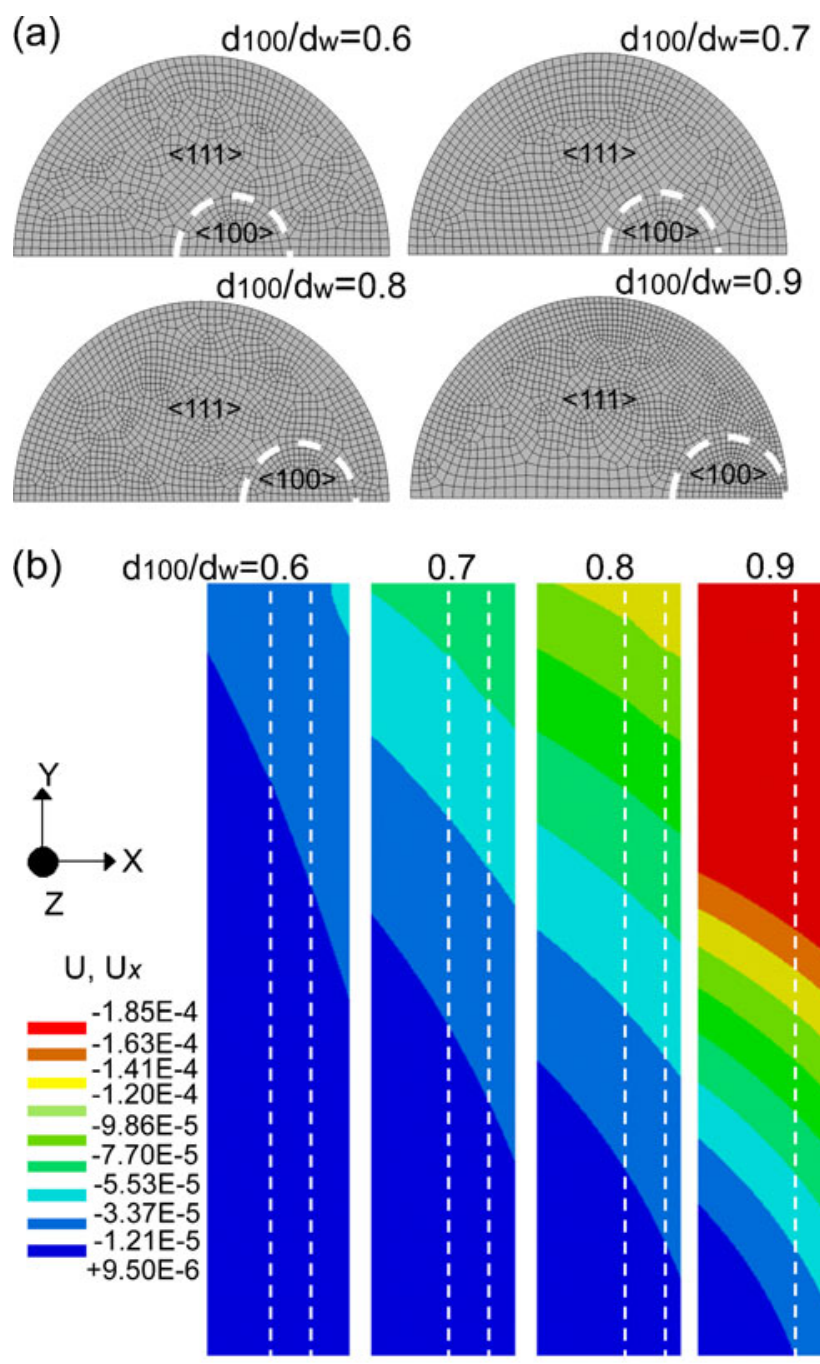

0.8

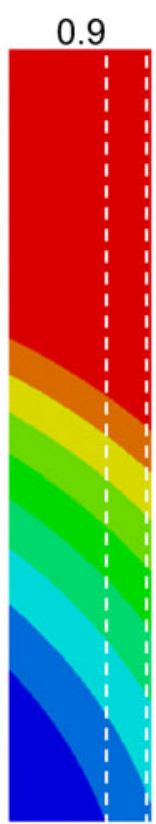

(c)

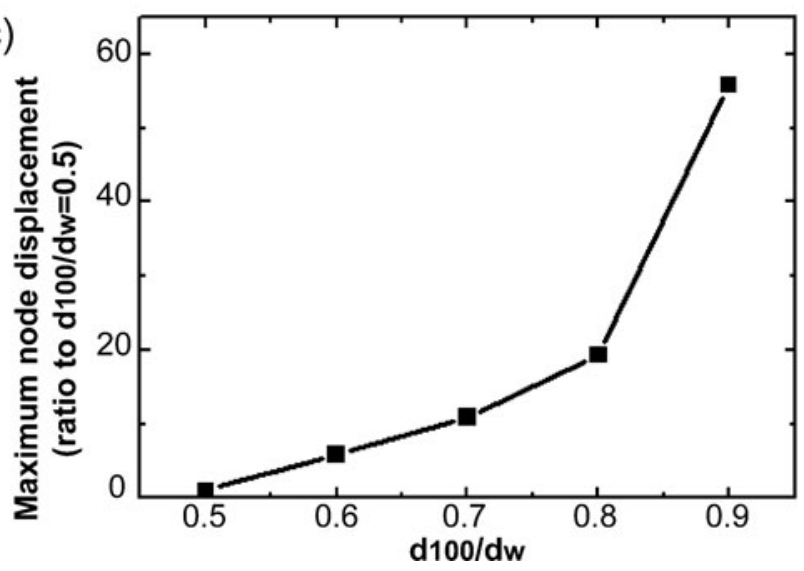

Fig. 4 Three-dimensional FEM models and simulations. a Normal views of four models applied in the FEM. b Spatial displacement contour maps in the $x$ direction of four models. c Selected node displacement in $x$ direction

assumed to be $5 \mu \mathrm{m}$ based on our EBSD measurement results for the $20 \mu \mathrm{m}$ diameter gold wire. All of the mechanical properties of our research models are based on gold, but the Young's modulus of each crystal direction is applied based on the calculated results.

It is expected that the deformation shapes of the tensioned gold wire are different depending on the location of the $<100>$ direction in the wire. In this FEM research, it is assumed that the bottoms of the wires are fixed, as the gold bonding wires are bonded to a metal pad. The tensile forces are applied to the upper side of each bonding wire in the FEM models [26]. Based on the location of the $<100>$ direction, four models are determined and the same forces are applied to each. As shown in Fig. 4a, the location of the $<100>$ direction in the four models is represented by $d_{100} / d_{\mathrm{w}}$ and have approximate values of $0.6,0.7,0.8$, and 0.9 , respectively.

Figure $4 \mathrm{~b}$ shows the contour of spatial displacement in the $x$ direction of the nodes in each model. All of the models in Fig. 4b correspond to those in Fig. 4a. The wire models adopted in our FEM study are assumed to have a length of $120 \mu \mathrm{m}$ to reduce the computational cost, even though the actual bonding wires have a length of more than $1 \mathrm{~mm}$ [27]. The dotted line in the models indicates the location of the $<100>$ direction in the bonding wire models. All of the models show that the deformations caused by the tensile force are asymmetric and the right sides of the bonding wire models have more deformation than the left sides. The difference in the Young's modulus between the $<111>$ and $<100\rangle$ directions is one reason for the asymmetric deformation of the bonding wire models. In general, the value of the Young's modulus indicates the stiffness and resistance to permanent deformation. In this regard, the simulated FEM models in Fig. $4 \mathrm{~b}$ shows that the deformation caused by the bonding force is focused on the area where the $<100>$ directions are located. Thus, the degree of $d_{100} / d_{\mathrm{w}}$ texture affects the asymmetric deformation of the bonding wire. The model with $d_{100} / d_{\mathrm{w}}=0.6$ shows a maximum spatial displacement of $-3.37 \mathrm{E}-5$ in the $x$ direction at the end of the wire. However, this spatial displacement value is based on the FEM models that have a wire length of $120 \mu \mathrm{m}$. As mentioned above, the bonding wire used in the devices has a length of more than $1 \mathrm{~mm}$ and this indicates that the actual bonding wire could have a greater spatial displacement at a specific point as the length of the wire increases. The results in Fig. 4b showing the concentration of the spatial displacement toward the end of the wire also confirms this hypothesis.

It is obvious that the bonding wires lean toward the left side because the $<100>$ direction is located on the right side of the bonding wire models. In the case of the model with $d_{100} / d_{\mathrm{w}}=0.9$, its $<100>$ direction is located almost at the surface of the gold bonding wire, and it shows a maximum spatial displacement of $-1.85 \mathrm{E}-4 \mu \mathrm{m}$ in the $x$ direction, which is almost one order of magnitude higher than the value of $d_{100} / d_{\mathrm{w}}=0.6$. 
In Fig. 4c, the curve of maximum node displacement in the $x$ direction shown in Fig. $4 \mathrm{~b}$ (ratio to $d_{100} / d_{\mathrm{w}}=0.5$ ) versus $d_{100} / d_{\mathrm{w}}$ is shown. In our FEM study, the node displacement of the $x$ direction is considered, because $x$ is the most unfavorable direction from the point of view of the bonding stability and mechanical durability of the IC. As already shown in Fig. 4b, when moving away from the center of the wires in the $<100>$ direction, the bonding wires lean more to the opposite side of the $<100>$ direction. All of the models in the FEM study show that the maximum node displacement is proportional to the value of $d_{100} / d_{\mathrm{w}}$ and this means that the higher the value of $d_{100} / d_{\mathrm{w}}$, the more the gold wire leans against the other gold bonding wires. Even in the case of $d_{100} / d_{\mathrm{w}}$ showing a value of 0.6 , the node displacement in the $x$ direction indicates the fivefold amount of $d_{100} /$ $d_{\mathrm{w}}=0.5$, which may be responsible for the severe leaning problem shown in Fig. 1b. What is more, this spatial displacement ratio of $d_{100} / d_{\mathrm{w}}$ is expected to have a higher value depending on the length of the bonding wire. When the value of $d_{100} / d_{\mathrm{w}}$ goes to 0.9 , the maximum node displacement is exponentially increased, and this happens because the location of the $<100\rangle$ direction is extremely close to the surface of the gold bonding wire and this reduces the binding force from the interfaces that work to prevent the wire from leaning in the opposite direction.

\section{Conclusions}

In this research, we analyzed how the bonding wire straightness problem occur using EBSD and FEM analysis. By observing the SEM images of the wire dies, it can be seen that the dies have asymmetrical shapes near the wire reduction area. Asymmetrical dies lead to asymmetrical deformation of the bonding wire as confirmed by EBSD analysis. Considering that the $\mathrm{RD} / /<100>$ rotates to the $\mathrm{RD} / /<111>$ during the gold wire drawing process, it is thought that the gold wire undergoes asymmetrical deformation in the drawing process. We calculated the Young's modulus of each orientation and applied these to the FEM analysis. The positional deviation of the $<100>$ texture from the center line of the wire is indicated by the $d_{100} / d_{\mathrm{w}}$ value. The results show that as $d_{100} / d_{\mathrm{w}}$ changes from $0.5(<100>$ at the center) to $0.9(<100>$ at the surface of the wire), the maximum amount of spatial displacement is exponentially increased, because the Young's moduli of the $<111>$ and $<100>$ orientations were found to be 116.28 and $42.91 \mathrm{GPa}$, respectively.

Acknowledgment This research (paper) was performed for "the Material \& Component Technology Development Program" funded by the Ministry of Knowledge \& Economy (MKE) of Korea.

Open Access This article is distributed under the terms of the Creative Commons Attribution License which permits any use, distribution and reproduction in any medium, provided the original author(s) and source are credited.

\section{References}

1. Kang SH, Jung HS, Bang WH et al (2005) High tensile strength of drawn gold. Mater Sci Forum 495:907-912

2. Tomiyama S, Fukui Y (1982) Gold bonding wire for semiconductor applications. Gold Bull 15:43-50

3. Cho JH, Rollett AD, Cho JS, Park YJ, Park SH, Oh KH (2006) Investigation on cold-drawn gold bonding wire with serial and reverse-direction drawing. Mater Sci Eng, A 432:202-215

4. Yu C-F, Chan C-M, Chan L-C, Hsieh K-C (2011) Cu wire bond microstructure analysis and failure mechanism. Microelectron Reliab 51:119-124

5. Chen J, Lai YS, Wang YW, Kao CR (2011) Investigation of growth behavior of $\mathrm{Al}-\mathrm{Cu}$ intermetallic compounds in $\mathrm{Cu}$ wire bonding. Microelectron Reliab 51:125-129

6. Ji HJ, Li MY, Wang CQ, Bang HS (2007) Comparison of interface evolution of ultrasonic aluminum and gold wire wedge bonds during thermal aging. Mater Sci Eng, A 447:111-118

7. Elices M (2004) Influence of residual stresses in the performance of cold-drawn pearlitic wires. J Mater Sci 39:3889-3899

8. Yang F, Jiang JQ, Fang F, Wang Y, Ma C (2008) Rapid determination of residual stress profiles in ferrite phase of colddrawn wire by XRD and layer removal technique. Mater Sci Eng, A $486: 455-460$

9. Dillamore IL (1964) Factors affecting the rolling recrystallisation textures in F.C.C. metals. Acta Metall Mater 12:1005-1014

10. Wulff F, Breach CD, Dittmer K (2003) Crystallographic texture of drawn gold bonding wires using electron backscattered diffraction (EBSD). J Mater Sci Lett 22:1373-1376

11. Cho JH, Cho JS, Moon JT (2003) Recrystallization and grain growth of cold-drawn gold bonding wire. Metall Mater Trans 34 A: $1113-1125$

12. English AT, Chin GY (1965) On the variation of wire texture with stacking fault energy in F.C.C. metals and alloys. Acta Metall Mater 13:1013-1016

13. Seeger A (1964) The stacking-fault energy of gold and silver. Phil Mag 101:887-890

14. Hasani GH, Mahmudi R, Karimi-Taheri A (2010) On the strain inhomogeneity in drawn copper wires. Int J Mater Form 3:59-64

15. De Castro ALR, Campos HB, Cetlin PR (1996) Influence of die semi-angle on mechanical properties of single and multiple pass drawn copper. J Mater Process Tech 60:179-182

16. Rajan K, Petkie R (1998) Microtexture and anisotropy in wire drawn copper. Mater Sci Eng, A 257:185-197

17. Mateescu N, Ferry M, Xu W, Cairney JM (2007) Some factors affecting EBSD pattern quality of $\mathrm{Ga}^{+}$ion-milled face centered cubic metal surfaces. Mater Chem Phys 106:142-148

18. Matteson TL, Schwarz SW, Houge EC, Kempshall BW, Giannuzzi LA (2002) Electron backscattering diffraction investigation of focused ion beam surfaces. J Electron Mater 31:33-39

19. Noguchi K, Araki M, Ohno Y (2000) Preparation of transmission electron microscopy specimens of as-drawn gold wire. Scripta Mater 43:199-204

20. Hannula SP, Wanagel J, Li CY (1983) Evaluation of mechanical properties of thin wires for electrical interconnections. IEEE Trans Components Hybrids Manufact Technol 6:494-502

21. Meyers MA, Chawla KK (2009) Mechanical behavior of materials. New York, Cambridge

22. Espinosa HD, Prorok BC, Peng B (2004) Plasticity size effects in free-standing submicron polycrystalline FCC films subjected to pure tension. J Mech Phys Solid 52:667-668 
23. Wu B, Heidelberg A, Boland JJ (2005) Mechanical properties of ultrahigh-strength gold nanowires. Nat Mater 4:525529

24. Maksimov EA (2011) Reducing pressure on the rolls and tension in the asymmetric cold-rolling of strip. Metallurgist 54:753-757

25. Cheon BH, Kim HW, Lee JC (2011) Asymmetric rolling of strip-cast Al-5.5 $\mathrm{Mg}-0.3 \mathrm{Cu}$ alloy sheet: Effects on the formability and mechanical properties. Mater Sci Eng, A 528:5223-5227

26. Tian YH, Wang CQ, Zhou YN (2008) Bonding mechanism of ultrasonic wedge bonding of copper wire on $\mathrm{Au} / \mathrm{Ni} / \mathrm{Cu}$ substrate. T Nonferr Metal Soc 18:132-137

27. Groover R, Shu WK, Lee SS (1994) Wire bond loop profile development for fine-pitch long-wire assembly. IEEE Trans Semicond Manuf 7:393-399 